\title{
Comparative Preliminary Analysis of Umbilical Cord Blood-, Healthy Adult Peripheral Blood-, and Myocardial Infarct Peripheral Blood-derived Endothelial Progenitor Cells
}

\author{
Wireni Ayuningtyas ${ }^{1,2}$, Rachmawati Noverina ${ }^{1}$, Dedy Kurniawan ${ }^{1}$, Astrid F. Khairani ${ }^{3}$, Nur Atik ${ }^{3}$, Firman F. Wirakusumah ${ }^{4}$, \\ Ahmad Faried ${ }^{5 *}$ \\ ${ }^{1}$ Laboratory Animal and Stem Cells Research, PT Bio Farma (Persero), Bandung, Indonesia; ${ }^{2}$ Graduate School of Biomedical \\ Sciences, Fast-Track Master Program, Faculty of Medicine, Universitas Padjadjaran (FK UNPAD), Bandung, Indonesia; \\ ${ }^{3}$ Department of Biomedical Sciences, Faculty of Medicine, Universitas Padjadjaran (FK UNPAD), Bandung, Indonesia; \\ ${ }^{4}$ Department of Obstetrics and Gynecology, Faculty of Medicine, Universitas Padjadjaran (FK UNPAD), Dr. Hasan Sadikin \\ Hospital (RSHS), Bandung, Indonesia; ${ }^{5}$ Department of Neurosurgery and Oncology \& Stem Cell Working Group, Faculty of \\ Medicine, Universitas Padjadjaran (FK UNPAD), Dr. Hasan Sadikin Hospital (RSHS), Bandung, Indonesia
}

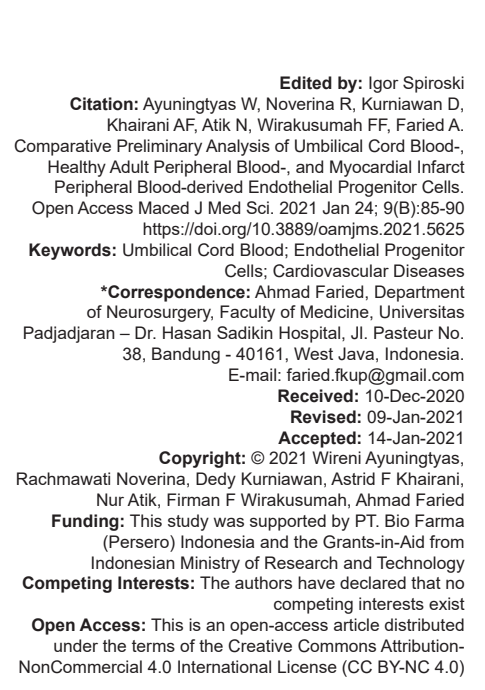

\section{Abstract}

BACKGROUND: Cardiovascular disease is a leading cause of death globally with the 287,000 deaths per years, characterized by declining of heart function caused by the reduction of heart capacity and lead to heart failure. Cell therapy using endothelial progenitor cells (EPCs) has a big potential for cardiovascular regeneration. EPCs are cells that have ability to differentiate into endothelial cells that can be mobilized and integrated into the defected blood vessel by angiogenesis.

AIM: We aimed to seek the superior EPCs derived from MNCs for functional improvement of advanced heart failure patient by cell therapy using EPCs.

MATERIALS AND METHODS: We did preliminary analysis to compare umbilical cord blood (UCB), healthy adult peripheral blood (PB)-, and myocardial infarct PB-derived EPCs characteristic and surface phenotypes. Different sources of each EPCs mononuclear cells were characterized by the expression of endothelial (cluster of differentiation [CD] 31, acethylated low-density lipoprotein, and von Willebrand) and hematopoietic stem cell (CD45, CD34, and CD133) surface markers with flow cytometry.

RESULTS: In this study, EPCs and the conditioned medium (CM) have been produced and characterized in laboratory scale by comparing several sources of EPCs for instance UCB, PB from healthy people, and patients with myocardia infarction. We have shown that EPC characterizations from each group were not significantly different, but vascular endothelial growth factor and hepatocyte growth factor in UBC-derived CM-EPCs were higher than in PB.

CONCLUSION: In conclusion, the UBC-derived EPCs might have a better potential for cardiovascular regeneration.

\section{Introduction}

Myocardial infarction (MI) results in reduction of heart pumping capacity and subsequently lead to heart failure. Despite the innovation in heart failure therapies including drugs and devices, but the morbidity and mortality of heart failure remain high. Patients with heart failure patients were responsible for 11 million physician visits each year and more hospitalizations than all forms of cancer combined [1]. More than half of myocardial infarction develop heart failure and die within five years. Heart failure contributes approximately 287,000 deaths a year. Sudden death is common in heart failure patient (6-9x vs general population). Heart failure contributes approximately 287,000 deaths a year. Sudden death is common in heart failure patient (6-9x vs. general population). Moreover, there was $12 \%$ decreased of deaths from heart failure per decade over the past 50 years [2], [3], [4], [5]. Due to that, myocardial regeneration by increasing number of myocardiac cell has potentially to improve heart failure prognosis.

Circulating progenitor cells (CPCs) are mononuclear cells (MNCs)-derived primarily from the bone marrow that contributes to vascular repair and regeneration largely through paracrine mechanisms [6]. CPCs can be measured as MNCs expressing the cluster of differentiation (CD) 34 epitope; these cells have the potential to differentiate into endothelial, hematopoietic, and non-hematopoietic phenotypes [7]. Recently, one study demonstrated that low CPCs count as an indicative of impaired endogenous regenerative capacity [8]. It is generally accepted that circulating endothelial progenitor cells (EPCs) exist in the adult heart, and that they might be involved in restoration of cardiac vasculature after injury [9]. Therefore, this 
was a preliminary analysis to compare umbilical cord blood (UCB) -, healthy adult peripheral blood (PB)-, and myocardial infarct PB-derived EPCs characteristic and surface phenotypes; aim to seek the superior EPCs derived from MNCs for functional improvement of advanced heart failure patient by cell therapy using EPCs.

\section{Materials and Methods}

This study was approved by Faculty of Medicine, Universitas Padjadjaran Ethics Committee, Bandung, Indonesia. The UCB were obtained from Graha Bunda Hospital, Bandung with informed consent and approval from the mother, UCB from subjects with questionable health conditions are avoided, for example, difficult deliveries, infectious disease, hepatitis-positive, or sexually transmitted diseases; fresh PB samples were obtained from healthy people and patients with Ml obtained from Dr. Hasan Sadikin Hospital were collected and stored in a sterile blood bag containing anti-coagulant at $4^{\circ} \mathrm{C}$ until processing.

\section{UCBs and PB samples; EPC cultures and conditioned medium (CM) preparation}

On receipt of the $U C B$ s or $P B$ samples, it must be handled in an aseptic technique and processed in a Class II biological safety cabinet. MNCs were isolated out of $80-100 \mathrm{ml}$ of UCBs or PB samples by ficoll density-gradient centrifugation (Ficoll Paque Premium GE 17-5442-03), as described previously [10]. These cells were suspended in growth medium consisting of $X$ vivo-15 (Lonza), 20\% patient's serum or fetal bovine serum (FBS), $1 \mathrm{ng} / \mathrm{ml}$ human recombinant vascular endothelial growth factor (VEGF) ( $R$ and $D$ ), and $0.1 \mu \mathrm{mol} / \mathrm{L}$ Lipitor atorvastatin (Pfizer). Subsequently, cells were seeded into fibronectin plate. The isolated MNCs were also grown in 96-well plates under identical conditions to be used in the characterization of cells on the harvesting day. On the 7 days after blood collection, the CM was collected and concentrated for the characterization CM. After cell get confluence $80 \%$, adherent cells were detached using $0.5 \mathrm{mmol} / \mathrm{L}$ ethylenediaminetetraacetic acid, washed twice, and re-suspended in growth medium.

\section{Acetylated-low-density lipoprotein (Ac-LDL) metabolism as EPCs cell marker molecule}

UCB EPCs culture was carried out on 8 wells micro sterile glass (Matsunami, Japan) which had been coated with type I collagen (Sigma). After reaching confluence, the medium is replaced with a new medium which has been added Ac-LDL and labeled with fluorescent dye Alexa fluor 488 (green fluorescence, Invitrogen). Subsequent actions, incubated for $4 \mathrm{~h}$ at $37^{\circ} \mathrm{C}$. Visualization of cells that have metabolized Ac-LDL was observed using confocal laser scanning microscopy (NGO 510 Meta, Zeiss).

\section{Immunoflorescent technique to see EPCs markers}

UCB EPCs culture was cultured in sterile culture dishes consisting of 8 wells (Matsunami), then washed $2 x$ with phosphate-buffered saline (PBS). Fixation was carried out with $4 \%$ (w/v) cold paraformaldehyde (PFA) for $10 \mathrm{~min}$. EPCs were then washed again with PBS, then added blocking fluid consisting of $10 \%(\mathrm{v} / \mathrm{v})$ normal serum gout (NGS) and $0.4 \%(\mathrm{v} / \mathrm{v})$ Triton $\mathrm{X}-100$. Furthermore, the sample was incubated for $30 \mathrm{~min}$ at room temperature, then administered primary antibodies for $1 \mathrm{~h}$ at room temperature. The antibodies used as marker molecules in this study were: anti-von Willebrand factor (VWF) VIII (vWF, Santa Cruz); anti-CD-31 (platelet endothelial cell adhesion molecule 1 [PECAM-1], BD Pharmingen); and TO-PRO-3 (Molecular Probes). After administration of the first antibody, EPCs were washed again with PBS, the second antibody could be given in PBS (1:1,000 dilution) containing $3 \%(\mathrm{v} / \mathrm{v})$ NGS and $0.1 \%(\mathrm{v} / \mathrm{v})$ triton $\mathrm{X}-100$. Incubation is carried out for 30 mins at room temperature. The second antibody used Alexa Flour 488 (green fluorescence, Invitrogen), fluorescein isothiocyanate (FITC) (green fluorescence), and rodhamine (red fluorescence, Jackson Immuno Research). EPCs cells are washed, fixation is carried out with $4 \%$ (v/v) PFA for $10 \mathrm{~min}$ at room temperature. Fixation results are washed again, then given a slips cover. Specimens that have been made protected using a vector mounting mounting medium (Vector Laboratories) observed using confocal laser scanning microscopy (LSM 510 Meta, Zeiss).

\section{Immunophenotyping and immunocytochemistry}

Fluorescence activated cells (FACs) technique was used to determine the typical cell surface epitope profiles for instance CD34, CD45, and CD133. Briefly, early EPCs were incubated with antibodies at $4^{\circ} \mathrm{C}$ and dark condition 15 min then analyzed by Cell Quest Pro software. As an alternative approach to determine the phenotype of EPCs, immune-fluorescent staining was performed. Cells on 96-well plate were added with Dilac-LDL reagent, fixated with 3\% PFA, treated UEA-1 Lectin, and subjected to be stained by 4',6-diamidino2-phenylindole consecutively with appropriate incubation and washing with PBS in-between staining. Fluorescence is observed by microscope fluorescence in the dark condition. 


\section{EPCs-CM}

\section{Characterization of blood-derived}

The enzyme-linked immunosorbent assay (Elisa) technique was used to determine the concentration of growth factor VEGF and hepatocyte growth factor (HFG) within the EPC-CM.

\section{Results}

\section{Isolation and culture of UCB- and PB-derived EPCs}

In our study, EPCs have been succeed to be isolated from human UCB and PB (Figure 1a-c) by Ficoll density-gradient centrifugation. After 7 days of contact with fibronectin-plastic, the detached cell was removed and the medium was replaced every 3 days. Cobble-stone and spindle shape cell were observed under microscope (Figure 1d and e).

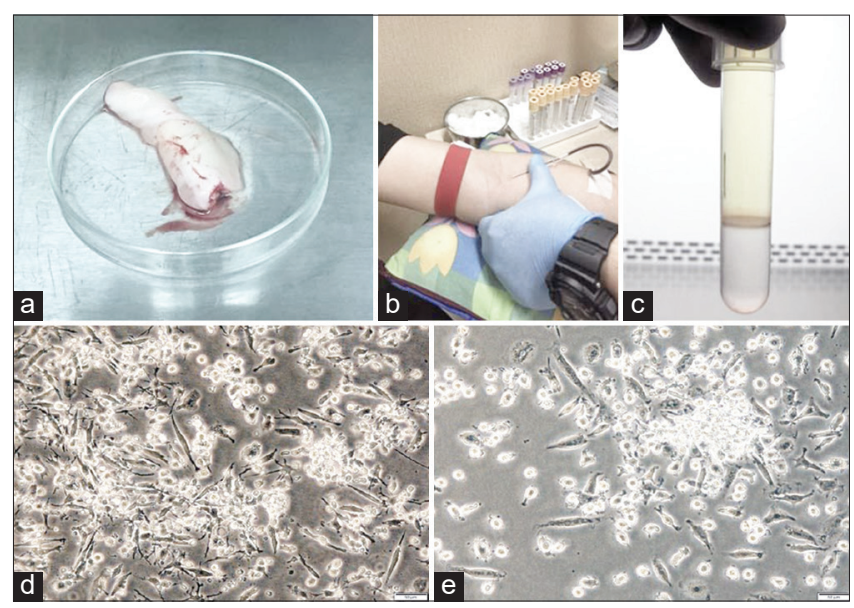

Figure 1: Endothelial progenitor cells have been succeed to be isolated from human umbilical cord blood and peripheral blood by Ficoll density-gradient centrifugation (a-c). After 7 days of contact with fibronectin-plastic, the detached cell was removed and the medium was replaced every 3 days. Cobble-stone and spindle shape cell was observed under microscope ( $d$ and e)

\section{molecule \\ Ac-LDL metabolism as EPCs cell marker}

The UCB-EPCs were cultured overnight on basement membrane matrix gel, capillary tubulelike structure formation was observed (Figure 2a). The Ac-LDL marker can be used to prove the existence of EPCs cells. Our EPCs shown of Ac-LDL immunoflorescent that looked like green dots evenly distributed in the cell cytoplasm (Figure 2b-d).

\section{Immunoflourescent technique to see EPCs}

\section{markers}

Immunofluorescent clotting factor VIII VWF is a specific marker of endothelial cells (EC), making it a standard marker molecule for EC in the culture system (Figure 3a); bromodeoxyuridine (BrdU) is used as a proliferation marker molecule. EPCs cells were then stained with immunoflorescent anti-CD31 PECAM-1 and To-Pro-3 molecules calculated in four regions considered representative; the value of viability reached $97-2.3 \%$ (Figure $3 b$ ).

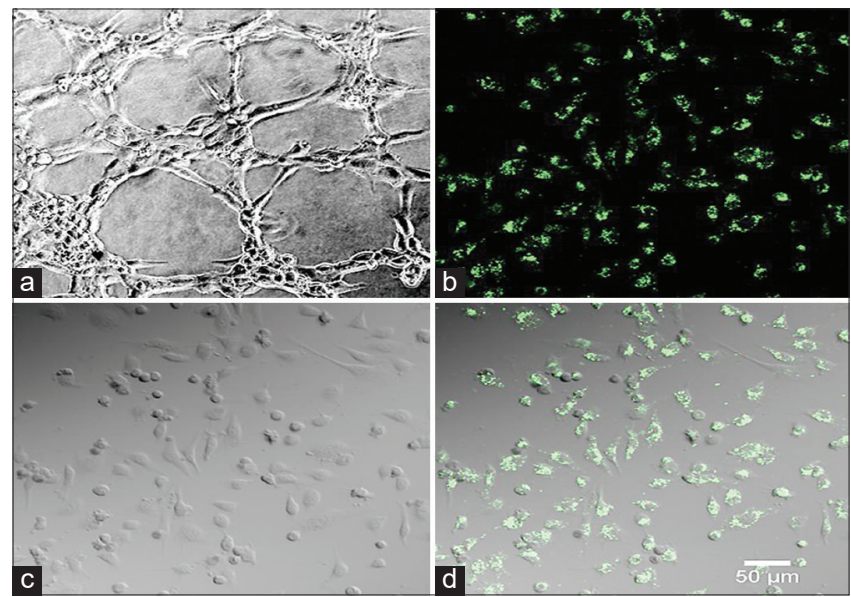

Figure 2: Umbilical cord blood -endothelial progenitor cells (EPCs) were cultured overnight on basement membrane matrix gel, capillary tubule-like structure formation was observed (a). The acetylatedlow-density lipoprotein marker was used to prove the existence of EPCs cells. Our EPCs shown of acetylated-low-density lipoprotein immunoflorescent that looked like green dots evenly distributed in the cell cytoplasm $(b-d)$
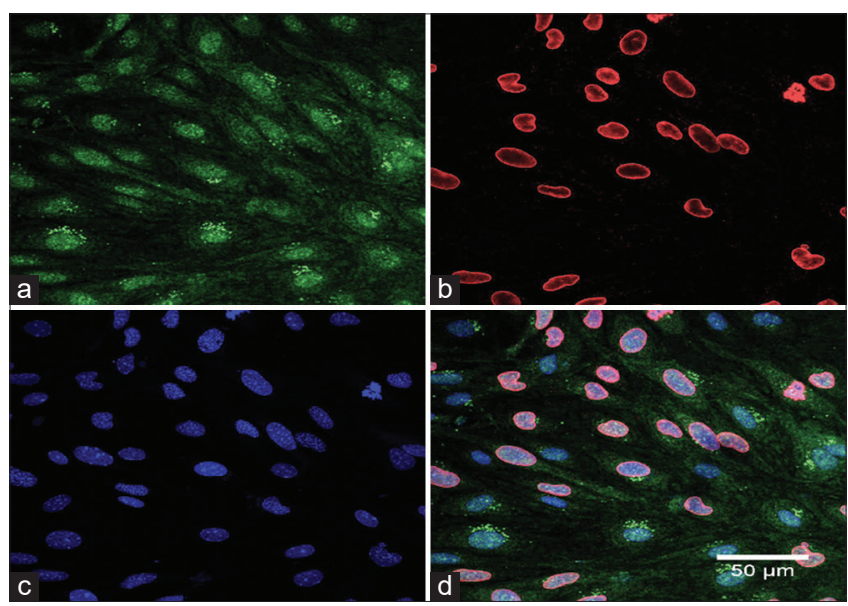

Figure 3: Immunofluorescent clotting factor VIII (VWF) is a a standard marker molecule for endothelial cells in the culture system (a); BrdU is used as a proliferation marker molecule. Endothelial progenitor cells were then stained with immunoflorescent anti-CD31 and To-Pro-3 molecules calculated in 4 regions considered representative; the value of viability reached $97 \pm 2.3 \%$ (b)

\section{Healthy and MI EPCs by immunophenotyping using FAC and immunohistochemistry}

Based on Figure $4 a$ and b, EPCs expressed proteins on their surfaces such as CD34 PE, CD45 FITC, and CD133 as receptors of VEGF. In addition, EPCs exhibited several characters such as have spindle shape morphology on fibronectin matrix, 
performed Ac-LDL endocytosis and bind to lectin (Figure 5).

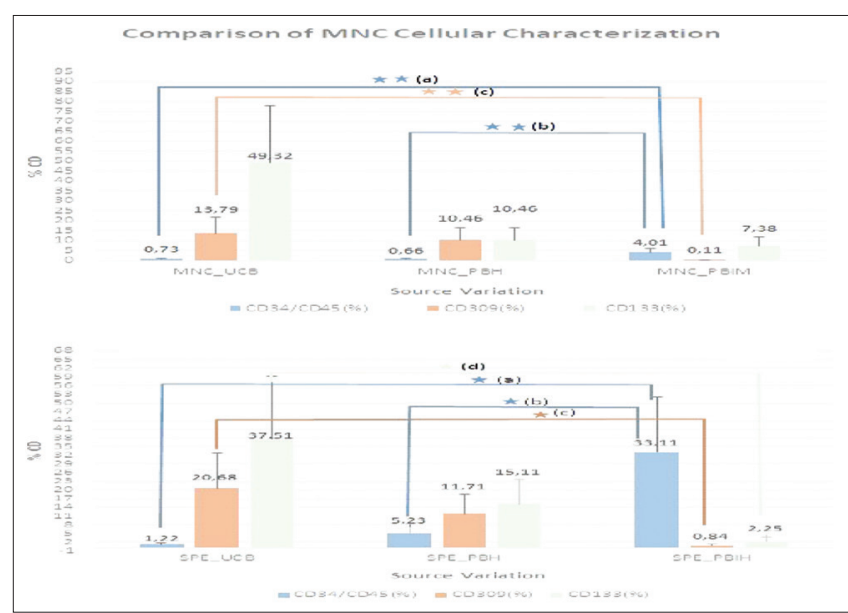

Figure 4: Mononuclear cells and endothelial progenitor cells expressed proteins on their surfaces such as CD34 PE, CD45 FITC, and CD133 as receptors of vascular endothelial growth factor ( $a$ and $b$ )

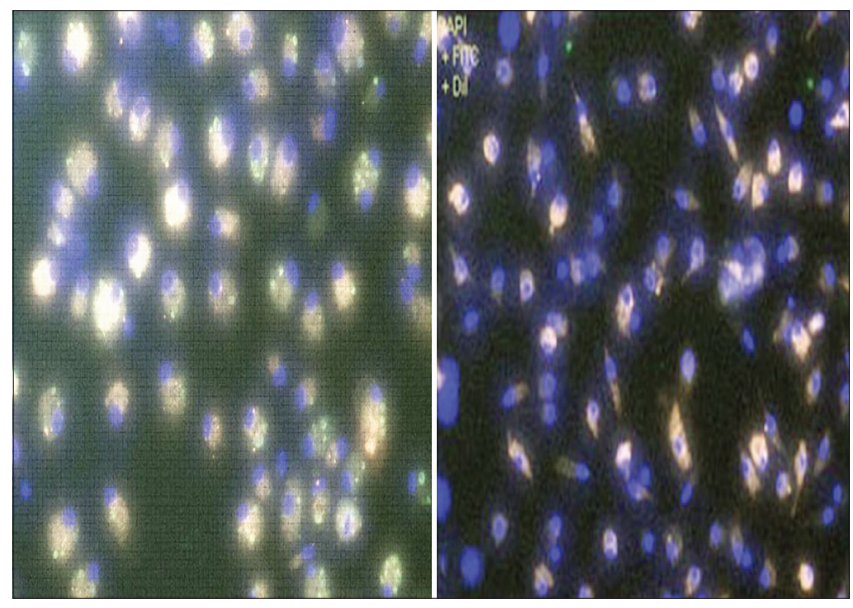

Figure 5: Endothelial progenitor cells exhibited several characters such as spindle shape morphology on fibronectin matrix, performed acetylated-low-density lipoprotein endocytosis and bind to lectin

\section{Characterization of MI, healthy, and UCB-derived EPCs-MNCs}

In this study, the characteristic of different isolated sources of each EPCs MNCs as follow: (I) The average MI PB MNCs (PBMNCS) age was 53 year old (YO), the average collected blood volume was $100 \mathrm{cc}$, the average isolated PB MNCs per ml was $1.165 \times 10^{6}$ with average viability which was $94.2 \%$. (II) The average Healthy PB MNCS age was $27 \mathrm{YO}$, the average collected blood volume was $90 \mathrm{cc}$, the average isolated PB MNCs per ml was $1.1 \times 10^{6}$ with average viability was $97.5 \%$. (III) The average UCB-MNCs age was $27 \mathrm{YO}$, the average collected blood volume was $80 \mathrm{cc}$, the average isolated MNCs per $\mathrm{ml}$ was $5.1 \times 10^{6}$ with average viability which was $96.8 \%$. The measurements of VEGF and HGF in CM-EPC have been done. This study revealed that EPCs produced VEGF and HGF as extracellular growth factor; both concentration in human
PB-derived EPC-CM decreased during culturing. However, VEGF concentration from UCB-derived EPC-CM increased during culturing up to $556 \mathrm{pg} / \mathrm{ml}$ using human serum in growth medium and $140 \mathrm{pg} / \mathrm{ml}$ using FBS in growth medium. HGF concentration from UCB-derived EPC-CM increased during culturing up to $500 \mathrm{pg} / \mathrm{ml}$ using human serum in growth medium and 900-3000 pg/ml using FBS in growth medium.

\section{Discussion}

Mesenchymal stem cells and EPCs from human fetal origin are promising sources for regenerative medicine, which has advantage over others resources based in its potential and efficacy [11], [12]. EPCs have been reported, which have role in vasculogenesis, angiogenesis, and re-endothelialization of injured vessels. Recently, study by Xue et al. indicates that even low-dose of EPCs transplantation may play a pro-angiogenic, anti-fibroblast, anti-fibrosis, and antinecrosis role and enhance cardiac function in a rat model [13]. The EPCs angiogenic potential limited by the absence of their natural biologic foundation, namely, smooth muscle pericytes also known as smooth muscle cells (SMCs); EPC-SMCs cell sheet transplantation attenuated myocardial dysfunction [14]. Further, statins treatment also shown augmented both number and function of EPCs [15].

Cord blood (CB) and PB considered as valuable sources of EPCs as they are both easy to obtain with noninvasive procedures [16]. However, isolated EPCs from UCB and adult PBMNCs exhibit different proliferation features and clonogenic potency [17]. In this present study, EPCs were isolated from three different sources, that is, UCB; healthy adult PB and myocardial infarct PB. EPCs can be identified by some characteristic such as expression of surface markers (CD34, CD31, KDR, and VWF) and endothelial functional assays such as endothelial tube formation and Ac-LDL uptake [16]. We observed EPCs obtained from all sources that were growing stably in 2 kinds of growth medium; with FBS and human-serum medium previously. However, there were apparent differences in the number of colonies and the time of appearance between CB-MNCs, PB-MNCs, and MI-MNCs. The number of EPCs-derived CB was 5-fold higher compared with PB-EPCs and MI-EPCs. In agreement with our result, EPCs intrinsically are available in a very low number $(<3-5 \%$ in the bone marrow and $0.0001-0.01 \%$ in the peripheral circulation), therefore need outside intervention to boost their number; development and optimize protocols for their undifferentiated in vitro expansion and manipulation to accentuate their functionality [18].

Nevertheless, 7 days after contact with fibronectin-plastic, EPCs-derived from all sources 
configure similar morphology into cobble-stone and spindle shape cells (Figure 1d and e). Furthermore, each EPCs from all sources were also cultured in membrane matrix gel. After overnight incubation, the cells formed capillary tubule-like structure formation. According to Gao et al., [16] one of the main characteristic function of EPCs is capability of cells to incorporate Ac-LDL. EPCs are able to degrade Ac-LDL due to its LDL-receptors without inhibit cell growth. However, the formation of capillary-like structures on Matrigel demonstrating ability to participate in angiogenesis [19]. The other aspect to confirm the authenticity of endothelial cells culture is by detecting VWF expression. VWF is an important component of hemostasis, binding platelets at sites of endothelial damage; it is produced in EC [20]. About $80 \%$ of the human umbilical vein EC population culture contain VWF [21].

Anti-CD31 PECAM-1 is also a significant group of endothelial markers. PECAM-1 and CD31 are a 130 $\mathrm{kDa}$ protein, which is exclusively expressed and widely distributed on EC [22]. PECAM-1 is heavily glycosylated transmembrane homophilic adhesion protein that is required for migration of leukocytes, playing a key role in removing aged neutrophils from the body and stabilize blood circulation [23]. The extracellular domain of CD31 is released during apoptosis of EC. This fragment circulates in the serum of patients suffering from MI [24]. In addition, BrdU and To-Pro-3 were used to observe proliferation activity of EPCs. The value of viability reached $97 \% \pm$ $2.3 \%$ (Figure $3 b$ ). In other words, no significant differences were identified between CB-EPC, PB-EPC, and MI-EPC either in endothelial functional assays such as endothelial tube formation and Ac-LDL uptake or in the expression of surface markers (CD34, CD133, CD45, and VWF). The differentiation capacity of progenitor cells is reduced in heart disease patients, which may hamper the clinical efficacy of autologous stem cell therapy; progenitor cells from outside patient body should be added to increase the success rate of cell therapy [25].

On the other hand, there are peculiar differences between the level of VEGF and HGF in CM of CB-EPC. This study revealed that EPCs-derived from $C B$ which is cultured in human serum produced higher concentration of VEGF than those which cultured in FBS. VEGF or vascular permeability factor was originally described as an EC-specific mitogen [26]. VEGF also induces the formation of the Willebrand factor and thrombogenesis and promotes collateral formation in the ischemic myocardium through the following mechanisms such as stimulates EC proliferation, regulates of several endothelial integrin receptors during sprouting of new blood vessels, and microvasular permeability [27], [28]. The potential of human serum as a substitute of FBS has been recognized for decades. However, human serum performed better activities in stimulating proliferation in several cells including EC [19]. We hypothesized that the increasing level of VEGF in human serum-CB-EPC is correlated with the escalation proliferation activity.
Meanwhile, endothelial produced higher HGF when cells were cultured in FBS. HGF is a mesenchymederived mitogen that also stimulates cell migration and mediate mesenchymal-epithelial and endothelial interactions, which contribute to tissue repair [29]. The mechanism underlying the differences between level concentration of HGF and VEGF produced by UCBEPCs was remain unclear.

\section{Conclusion}

Our study demonstrated that the superior sources of EPCs for cardiovascular disease therapy is UCB due to the large-number of cell harvested and the extracellular growth factor such as VEGF and HGF in CM-EPCs is higher compare the PB.

\section{Acknowledgment}

Wireni Ayuningtyas funded by PT. Bio Farma (Persero) Indonesia; Ahmad Faried supported by the Grants-in-Aid from Indonesian Ministry of Research and Technology (National Research and Innovation Agency) No. 16/E1/KPT/2020 for Basic Research.

\section{References}

1. Askoxylakis V, Thieke C, Pleger ST, Most P, Tanner J, Lindel K, et al. Long-term survival of cancer patients compared to heart failure and stroke: A systematic review. BMC Cancer. 2010;10(1):105. https://doi.org/10.1186/1471-2407-10-105 PMid:20307299

2. Levy D, Kenchaiah S, Larson MG, Benjamin EJ, Kupka MJ Ho KK, et al. Long-term trends in the incidence of and survival with heart failure. N Engl J Med. 2002;347(18):1397-402. https:// doi.org/10.1056/nejmoa020265

PMid:12409541

3. Roger VL, Weston SA, Redfield MM, Hellermann-Homan JP, Killian J, Yawn BP, et al. Trends in heart failure incidence and survival in a community-based population. JAMA. 2004;292(3):344-50. https://doi.org/10.1001/jama.292.3.344 PMID: 15265849

4. von Degenfeld G, Raake P, Kupatt C, Lebherz C, Hinkel R, Gildehaus FJ, et al. Selective pressure-regulated retroinfusion of fibroblast growth factor-2 into the coronary vein enhances regional myocardial blood flow and function in pigs with chronic myocardial ischemia. J Am Coll Cardiol. 2003;42(6):1120-8. https://doi.org/10.1016/s0735-1097(03)00915-x PMid:13678941

5. Raake P, von Degenfeld G, Hinkel R, Vachenauer R, Sandner $\mathrm{T}$, Beller $\mathrm{S}$, et al. Myocardial gene transfer by selective 
pressure-regulated retroinfusion of coronary veins: Comparison with surgical and percutaneous intramyocardial gene delivery. J Am Coll Cardiol. 2004;44(5):1124-9. https://doi.org/10.1016/j. jacc.2004.05.074

PMid: 15337228

6. UrbichC,DimmelerS. Endothelial progenitorcells:Characterization and role in vascular biology. Circ Res. 2004;95(4):343-53. https:// doi.org/10.1161/01.res.0000137877.89448.78

PMid:15321944

7. Fadini GP, Losordo D, Dimmeler S. Critical reevaluation of endothelial progenitor cell phenotypes for therapeutic and diagnostic use. Circ Res. 2012;110(4):624-37. https://doi. org/10.1161/circresaha.111.243386

PMid:22343557

8. Mehta A. Tahhan AS, Liu C, Liu C, Dhindsa DS, Nayak A, et al. Circulating Progenitor Cells in Patients With Coronary Artery Disease and Renal Insufficiency. J Am Coll Cardiol Basic Trans Science 2020;5(8):770-82.

9. Kovacic JC, Fuster V. Cell therapy for patients with acute myocardial infarction: ACCRUEd evidence to date. Circ Res. 2015;116(8):1287-90. https://doi.org/10.1161/ circresaha. 115.306323

PMid:25858059

10. Djuwantono T, Wirakusumah FF, Achmad TH, Sandra F, Halim D, Faried A. A comparison of cryopreservation methods: Slow-cooling vs. Rapid-cooling based on cell viability, oxidative stress, apoptosis, and CD34+ enumeration of human umbilical cord blood mononucleated cells. BMC Res Notes. 2011;4:371. https://doi.org/10.1186/1756-0500-4-371

PMid:21943045

11. Cantore S, Crincoli V, Boccaccio A, Uva AE, Fiorentino M, Monno G, et al. Recent advances in endocrine, metabolic and immune disorders: Mesenchymal stem cells (MSCs) and engineered scaffolds. Endocr Metab Immune Disord Drug Targets 2018;18(5):466-9. https://doi.org/10.2174/1871530318 666180423102905

PMid:29692270

12. Muniswami DM, Reddy LV, Amirtham SM, Babu S, Raj AN, Sen $D$, et al. Endothelial progenitor/stem cells in engineered vessels for vascular transplantation. J Mater Sci Mater Med. 2020;31(12):119. https://doi.org/10.1007/s10856-020-06458-7 PMid:33247781

13. Xue Y, Zhou B, Wu J, Miao G, Li K, Li S, Zhou J, Geng Y, Zhang P. Transplantation of Endothelial Progenitor Cells in the Treatment of Coronary Artery Microembolism in Rats. Cell Transplant. 2020;29:1-8. doi: 10.1177/0963689720912688. PMid:32233803

14. Shudo Y, Goldstone AB, Cohen JE, Patel JB, Hopkins MS, Steele AN, et al. Layered smooth muscle cell-endothelial progenitor cell sheets derived from the bone marrow augment postinfarction ventricular function. J Thorac Cardiovasc Surg. 2017;154(3):955-63. https://doi.org/10.1016/j.jtcvs.2017.04.081 PMid:28651946

15. Sandhu K, Mamas M, Butler R. Endothelial progenitor cells: Exploring the pleiotropic effects of statins. World $\mathrm{J}$ Cardiol. 2017;9(1):1-13. https://doi.org/10.4330/wjc.v9.i1.1 PMid:28163831

16. Gao X, Yourick JJ, Sprando RL. Comparative transcriptomic analysis of endothelial progenitor cells derived from umbilical cord blood and adult peripheral blood: Implications for the generation of induced pluripotent stem cells. Stem Cell Res. 2017;25:202-12. https://doi.org/10.1016/j.scr.2017.11.004 PMid:29156376

17. Gumina DL, Su EJ. Endothelial progenitor cells of the human placenta and fetoplacental circulation: A potential link to fetal, neonatal, and long-term health. Front Pediatr. 2017;5:41. https:// doi.org/10.3389/fped.2017.00041

PMid:28361046

18. Haider KH, Aziz S, Al-Reshidi MA. Endothelial progenitor cells for cellular angiogenesis and repair: Lessons learned from experimental animal models. Regen Med. 2017;12(8):969-82. https://doi.org/10.2217/rme-2017-0074

PMid:29215316

19. Zhang P, Policha A, Tulenko T, DiMuzio P. Autologous human plasma in stem cell culture and cryopreservation in the creation of a tissue-engineered vascular graft. J Vasc Surg. 2016;63(3):805-14. https://doi.org/10.1016/j.jvs.2014.10.015 PMid:25499702

20. Lenting PJ, Christophe OD, Denis CV. von Willebrand factor biosynthesis, secretion, and clearance: Connecting the far ends. Blood. 2015;125(13):2019-28. https://doi.org/10.1182/ blood-2014-06-528406

PMid:25712991

21. Kudryavtsev IV, Garnyuk VV, Nadeev AD, Goncharov NV. Hydrogen peroxide modulates expression of surface antigens by human umbilical vein endothelial cells in vitro. Biochem Moscow Suppl Ser A 2014;8:97-102. https://doi.org/10.1134/ s1990747813050103

22. Goncharov NV, Nadeev AD, Jenkins RO, Avdonin PV. Markers and biomarkers of endothelium: When something is rotten in the state. Oxid Med Cell Longev. 2017;2017:9759735. https://doi. org/10.1155/2017/9759735

PMid:29333215

23. Yamamoto K, de Waard V, Fearns C, Loskutoff DJ. Tissue distribution and regulation of murine von Willebrand factor gene expression in vivo. Blood 1998;92(8):2791-801. https://doi. org/10.1182/blood.v92.8.2791.420k24_2791_2801 PMid:9763564

24. Riccieri V, Stefanantoni K, Vasile M, Macrì V, Sciarra I, lannace N, et al. Abnormal plasma levels of different angiogenic molecules are associated with different clinical manifestations in patients with systemic sclerosis. Clin Exp Rheumatol. 2011;29(2):S4652. https://doi.org/10.1111/1756-185x.14002 PMid:21586218

25. Nollet E, Hoymans VY, Rodrigus IR, De Bock D, Dom M, Vanassche $\mathrm{B}$, et al. Bone marrow-derived progenitor cells are functionally impaired in ischemic heart disease. J Cardiovasc Transl Res. 2016;9(4):266-78. https://doi.org/10.1007/s12265-016-9707-z PMid:27456951

26. Ferrara N, Houck K, Jakeman L, Leung DW. Molecular and biological properties of the vascular endothelial growth factor family of proteins. Endocr Rev. 1992;13(1):18-32. https://doi. org/10.1210/edrv-13-1-18

PMid:1372863

27. Primo L, Seano G, Roca C, Maione F, Gagliardi PA, Sessa R, et al. Increased expression of alpha6 integrin in endothelial cells unveils a proangiogenic role for basement membrane. Cancer Res. 2010;70(14):5759-69.

PMid:20570893

28. Petyunina OV, Kopytsya MP, Rudyk IS, Isayeva GS. In: Berezin AE, editor. Promising Role of Vascular Endothelial Growth Factor-a in Risk Stratification After PCI, Vascular Access Surgery-Tips and Tricks. United State: IntechOpen; 2019. https://doi.org/10.5772/intechopen.82712

29. Xin X, Yang S, Ingle G, Zlot C, Rangell L, Kowalski J, et al. Hepatocyte growth factor enhances vascular endothelial growth factor-induced angiogenesis in vitro and in vivo. Am J Pathol. 2001;158(3):1111-20. https://doi.org/10.1016/ s0002-9440(10)64058-8

PMid:11238059 